\title{
Генетическое разнообразие и антиоксидантный потенциал сортов перца сладкого (Capsicum annuum L.) сибирской селекции
}

\author{
И.В. Тоцкий ${ }^{1} \otimes$, Е.И. Гордеева ${ }^{1}$, Т.В. Кукоева ${ }^{1}$, А.Ф. Петров ${ }^{2}$, Р.С. Юдина ${ }^{1}$, Е.К. Хлесткина ${ }^{1,3}$, О.Ю. Шоева $^{1}$ \\ 1 Федеральный исследовательский центр Институт цитологии и генетики Сибирского отделения Российской академии наук, Новосибирск, Россия
2 Новосибирский государственный аграрный университет, Новосибирск, Россия
3 Федеральный исследовательский центр Всероссийский институт генетических ресурсов растений имени Н.И. Вавилова (ВИР), Санкт-Петербург, \\ Россия
}

() Авторы, 2019

(ه) totsky@bionet.nsc.ru

\begin{abstract}
Аннотация. Перец сладкий (Capsicum annuum L.) - экономически значимая пасленовая культура. Его плоды служат источником макро-, микроэлементов, витаминов А и С, каротиноидов, различных кислот, сахаров, а также полифенольных соединений, привлекающих особое внимание благодаря своим антиоксидантным свойствам, важным для профилактики и лечения различных заболеваний человека. В настоящей работе с помощью генотипирования SSR-маркерами проведено исследование генетического сходства десяти сортов перца сибирской селекции, имеющих желтую, красную и фиолетовую окраску плодов, и оценен антиоксидантный потенциал фракции водорастворимых пигментов. По данным микросателлитного генотипирования перцы были разделены на три кластера: в первый вошли сорта Красавец Приобья и Гранатовый браслет, а также Ятаган и гибрид, полученный от сорта Сибирский экспресс, сгруппированные попарно; второй кластер составили Бегемот и 3олото Сибири, а третий - Кавалер и Сибирский князь. Сорта Мавр и Солнечный не вошли ни в один из кластеров, что указывает на их генетическую удаленность от других сортов перца, в том числе друг от друга. Суммарное содержание водорастворимых антиоксидантов, экстрагированных в условиях, максимально приближенных к таковым в желудочно-кишечном тракте, варьировало от 0.75 мкг-экв. ГК/г у красноплодного Бегемота до 1.54 мкг-экв. ГК/г у фиолетово-красноплодного гибрида, полученного от сорта Сибирский экспресс. С помощью непараметрического критерия Краскела - Уоллиса было показано, что на антиоксидантные свойства экстрактов влияют факторы «генотип» и «окраска плодов». Фиолетовоплодные сорта перца имели наибольшую антиоксидантную активность, статистически достоверно отличающуюся от таковой у красноплодных перцев. Группа желтых перцев по суммарному содержанию антиоксидантов занимала промежуточное положение между фиолетовои красноплодными перцами и статистически не отличалась от них. Между содержанием антоцианов, оцененным спектрофотометрически при длине волны 530 нм, и антиоксидантной активностью выявлена слабая, но достоверная корреляция $\left(r_{s}=0.41, p \leq 0.05\right)$.
\end{abstract}

Ключевые слова: молекулярные маркеры; микросателлиты; кластерный анализ; антоцианы.

Благодарности. Работа выполнена в рамках бюджетного проекта № 0259-2019-0011.

\section{Genetic diversity and antioxidant properties of the bell pepper (Capsicum annuum L.) cultivars bred for Siberia}

\author{
I.V. Totsky ${ }^{1} \otimes$, E.I. Gordeeva ${ }^{1}$, T.V. Kukoeva ${ }^{1}$, A.F. Petrov ${ }^{2}$, R.S. Yudina ${ }^{1}$, E.K. Khlestkina ${ }^{1}{ }^{3}$, O.Yu. Shoeva ${ }^{1}$ \\ ${ }^{1}$ Institute of Cytology and Genetics, Siberian Branch of the Russian Academy of Sciences, Novosibirsk, Russia \\ ${ }^{2}$ Novosibirsk State Agrarian University, Novosibirsk, Russia \\ ${ }^{3}$ Federal Research Center the N.I. Vavilov All-Russian Institute of Plant Genetic Resources (VIR), 42, 44 Bolshaya Morskaya Str., St. Petersburg, 190000 Russia
}

Autors, 2019

凶 totsky@bionet.nsc.ru
Abstract. Bell pepper (Capsicum annuum L.) is an economically significant crop. Its fruits are a source of macro-, microelements, vitamins A and C, carotenoids, various acids, sugars, as well as polyphenolic compounds, which attract special attention due to their antioxidant properties that are important for the prevention and treatment of various human diseases. In the present study, in addition to the 
genetic similarity of ten pepper cultivars with yellow, red and purple color of fruits bred for Siberian region, the antioxidant potential of the water-soluble pigments fraction of these peppers was studied. Based on microsatellite genotyping, peppers were divided into three clusters. The first cluster included four cultivars that grouped in two subclasters: Krasavec Priob'ya and Granatovyj braslet; Yatagan and hybrid obtained from the cultivar Sibirskij ekspress. Second cluster consisted of Begemot and Zoloto Sibiri. The third cluster included Kavaler and Sibirskij knyaz. Cultivars Mavr and Solnechnyj were not included in any of the clusters, which indicates their genetic distance from each other as well as from the other pepper cultivars. The total content of water-soluble antioxidants extracted under conditions close to those ones in the gastrointestinal tract ranged from $0.75 \mu \mathrm{g}$ of gallic acid equivalent/g in red fruits of Begemot up to $1.54 \mu \mathrm{g}$ of gallic acid equivalent/g in the purple-red fruits of hybrid obtained from the cultivar Sibirskij ekspress. Using the non-parametric Kruskal - Wallis test, it was shown that the factors "genotype" and "fruit color" influence on the antioxidant properties of extracts. Pepper cultivars with purple fruits had the highest antioxidant activity, statistically different from that one of the red peppers. The total antioxidants content of the yellow peppers was an intermediate between purple and red peppers and did not statistically differ from them. A weak but significant correlation was revealed between the anthocyanin content, which was evaluated by a spectrophotometer at a wavelength $530 \mathrm{~nm}$, and antioxidant activity $\left(r_{s}=0.41, p \leq 0.05\right)$.

Key words: molecular markers; microsatellites; cluster analysis; anthocyanins.

\section{Введение}

В последнее время во всем мире, в том числе в нашей стране, особую популярность приобретают функциональные продукты питания, содержащие физиологически активные, ценные и безопасные для здоровья компоненты с известными физико-химическими характеристиками, для которых выявлены и научно обоснованы полезные для сохранения и улучшения здоровья свойства (Фотев и др., 2018). Интерес к потреблению плодов перца Capsicum annum L. в качестве функционального продукта питания в значительной степени обусловлен содержанием в них биологически активных соединений. Плоды перца служат источником макро-, микроэлементов, витаминов А и С, различных кислот, сахаров, алкалоидов, а также они богаты полифенольными соединениями и каротиноидами, обладающими антиоксидантными свойствами, потребление которых снижает риск воспалительных процессов, рака, сердечно-сосудистых заболеваний, диабета и ожирения (Ahuja et al., 2006; Rao, Rao 2007; Meghvansi et al., 2010; Zimmer et al., 2012).

Окраска плодов перца - одна из его важных продовольственных характеристик - может быть зеленой, желтой, оранжевой, красной, фиолетовой, коричневой или черной. Пигменты, определяющие такое разнообразие цветов, относятся к флавоноидным и каротиноидным соединениям, которые могут присутствовать в плодах перца в различных комбинациях и соотношениях, придавая каждому генотипу уникальные биохимические свойства. Так, красный перец накапливает каротиноиды ликопин, капсантин и его изомер капсорубин. В желтом болгарском перце преобладают каротиноиды зеаксантин, $\beta$-каротин, $\beta$-криптоксантин, виолаксантин, антраксантин и кукурбитаксантин и содержится совсем мало ликопина. Зеленый болгарский перец содержит каротин и ликопин. Фиолетовая окраска обусловлена флавоноидными пигментами антоцианами (Nadeem et al., 2011). Разные системы генов и клеточные механизмы контролируют синтез антоцианов и каротиноидов в плодах перца (Liu et al., 2018; Ohmiya et al., 2019). Bce названные соединения входят в антиоксидантный пул, однако каротиноиды относятся к жиро-, а антоцианы - к водорастворимым пигментам. Сравнение антиоксидантной активности фенольной и масляной (каротиноиды и а-токоферол) фракций показало, что первая вносит наибольший вклад в антиоксидантный потенциал перцев (Blanco-Ríos et al., 2013).

Перец - теплолюбивая культура: его родиной являются Мексика, Центральная Америка и северная часть Южной Америки. Семена жгучего стручкового перца были импортированы в Испанию в 1493 году. Позже вместе с турецкими завоевателями прибыли на территорию Болгарии, где местные селекционеры вывели из жгучего перца сладкие крупноплодные сорта, которые распространились далее по Европе и Азии (Basu, De, 2003). Сегодня сладкий перец распространен далеко за пределами центра своего происхождения и возделывается даже в таких районах со сложными климатическими условиями, как Западная Сибирь, где были выведены и успешно культивируются в открытом грунте местные адаптированные сорта перцев. Цель настоящей работы исследование генетического разнообразия сортов перца сибирской селекции и антиоксидантного потенциала фракции водорастворимых пигментов, выделенных из плодов перца с различной окраской.

\section{Материалы и методы}

\section{Растительный материал}

Для работы были выбраны сорта перца сладкого селекции ЦСБС СО РАН (Новосибирск), СибНИИРС (Новосибирск), Зсоос ВНИИО (Барнаул) и агрофирмы «Седек» (Домодедово), адаптированные для культивирования в открытом грунте в условиях Западной Сибири, а также гибрид, полученный от сорта Сибирский экспресс (далее - гибрид Сибирского экспресса), отличающийся от исходного сорта красно-фиолетовой окраской плода и большей крупноплодностью (рис. 1). Характеристики сортов перца представлены в таблице 1. Семена перцев были получены из СибНИИРС и ЦСБС СО РАН.

\section{Выделение ДНК, генотипирование и кластерный анализ} Выделение ДНК из листьев перца проводили с использованием набора DNeasy Plant Mini Kit (Qiagen) согласно инструкции производителя. Для генотипирования сортов овощного перца использовали полиморфные микросателлитные маркеры, меченные на 

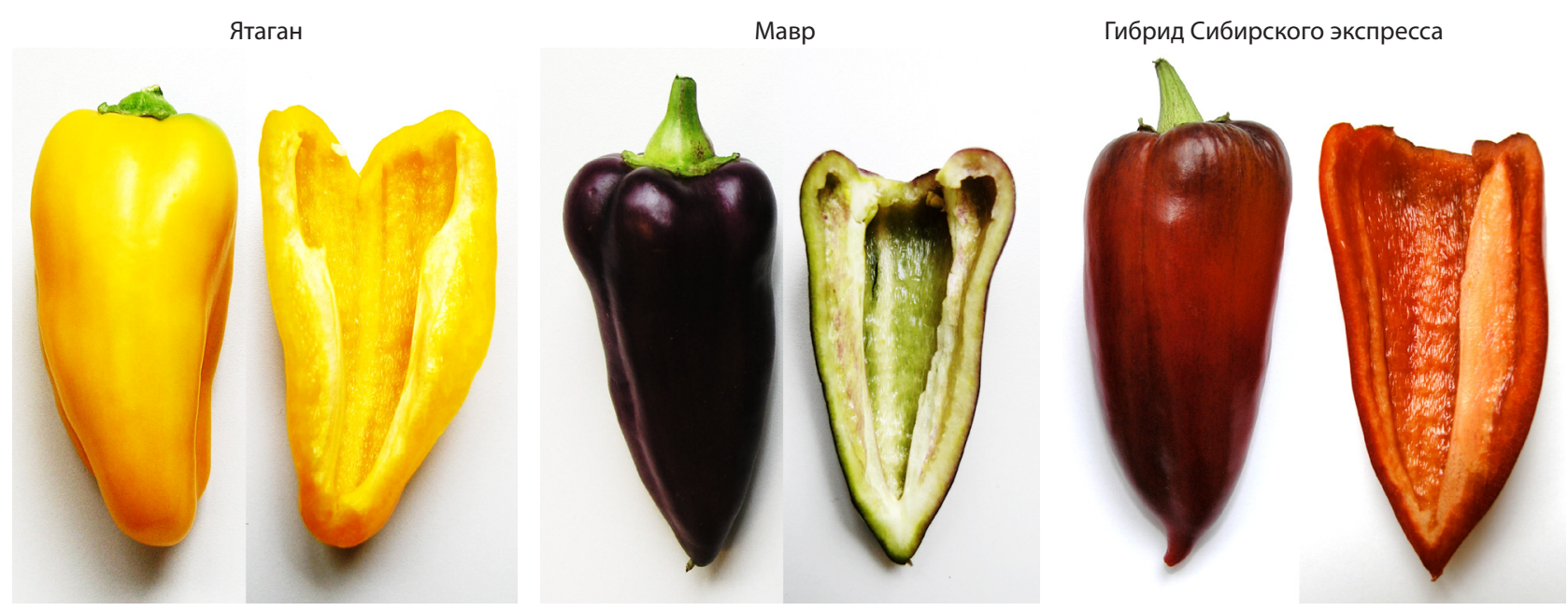

Сибирский князь
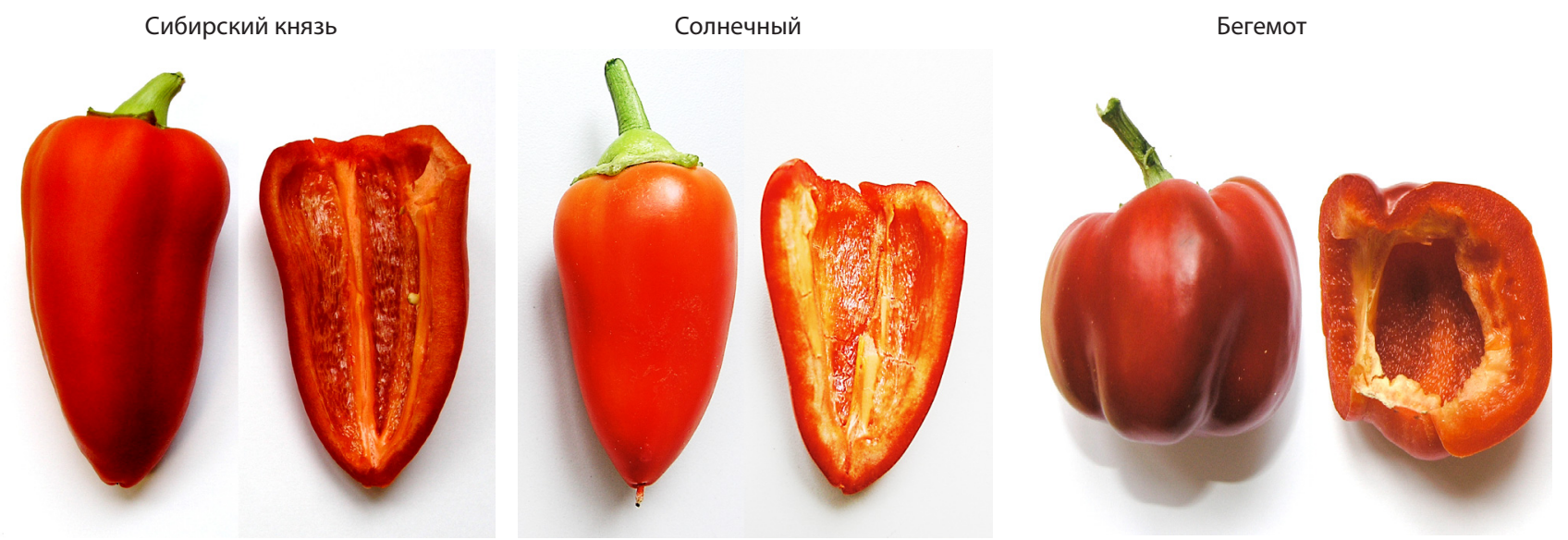

Рис. 1. Сибирские сорта перца сладкого, используемые в исследовании.

Figure 1. Siberian cultivars of bell pepper used in the current study.

Таблица 1. Характеристика сортов перца сладкого, используемых в работе

Table 1. Characteristics of the bell pepper cultivars used in the current study

\begin{tabular}{llllll} 
№ & Сорт & $\begin{array}{l}\text { Окраска плода в био- } \\
\text { логической спелости }\end{array}$ & $\begin{array}{l}\text { Срок } \\
\text { созревания }\end{array}$ & Масса плода, г & $\begin{array}{l}\text { Организация-создатель } \\
\text { сорта }\end{array}$ \\
\hline 1 & Бегемот & Красная & Среднеспелый & 170 & ССС СО РАН \\
\hline 2 & Гранатовый браслет & Красная & Раннеспелый & 180 & ЦСБС СО РАН \\
\hline 3 & Золото Сибири & Желтая & Среднеспелый & 250 & ЗСООС ВНИИО \\
\hline 4 & Кавалер & Красная & Раннеспелый & 80 & СибНИИРС \\
\hline 5 & Красавец Приобья & Красная & Раннеспелый & 152 & агрофирма «Седек» \\
\hline 6 & Мавр & Фиолетовая & Раннеспелый & 110 & ЗСООС ВНИИО \\
\hline 7 & Сибирский князь & Фиолетовая & Раннеспелый & 150 & ЦСБС СО РАН \\
\hline 8 & Сибирский экспресс & Красная & Раннеспелый & 50 & СибНИИРС \\
\hline 9 & Солнечный & Красная & Раннеспелый & 80 & ЦСБС СО РАН \\
\hline 10 & Ятаган & Желтая & Среднеспелый & 80 & \\
\hline
\end{tabular}


Таблица 2. Микросателлитные маркеры, используемые для генотипирования сортов перца сладкого

Table 2. Microsatellites used for genotyping of the bell pepper cultivars

\begin{tabular}{|c|c|c|c|c|c|c|}
\hline Маркер & Структура праймеров & Повтор & Длина, нукл. & Т отжига, ${ }^{\circ} \mathrm{C}$ & Метка & Источник \\
\hline Hpsm1-5 & $\begin{array}{l}\text { F:ccaaacgaaccgatgaacactc; } \\
\text { R:gacaatgttgaaaaaggtggaagac }\end{array}$ & $(\mathrm{AT})_{11}(\mathrm{GT})_{17}$ & 311 & 55 & FAM & Lee et al., 2004 \\
\hline Epms310 & $\begin{array}{l}\text { F:tgggaagagaaattgtgaaagc; } \\
\text { R:aggaaacatggttcaatgcc }\end{array}$ & $(\mathrm{CAT})_{13}$ & $140-172$ & 60 & FAM & Nagy et al., 2007 \\
\hline Epms331 & $\begin{array}{l}\text { F:aacccaatccccttatccac; } \\
\text { R: gcattagcagaagccatttg }\end{array}$ & $(C A)_{10}$ & $92-107$ & 60 & R6G & Nagy et al., 2007 \\
\hline Epms397 & $\begin{array}{l}\text { F:gcaccctcccaatacaaatc; } \\
\text { R:gatcacggagaaagcaaagg }\end{array}$ & $(C A)_{20}$ & $102-117$ & 60 & FAM & Nagy et al., 2007 \\
\hline Epms419 & $\begin{array}{l}\text { F:ttcaggtgcaggtatcatcg; } \\
\text { R:gggtacttgtccatttatccag }\end{array}$ & $(\mathrm{AAT})_{6}$ & $224-248$ & 60 & R6G & Nagy et al., 2007 \\
\hline
\end{tabular}

5'-конце флуоресцентными красителями FAM и R6G (табл. 2). Meченые праймеры синтезировали в ООО «Синтол» (Россия), немеченые - в ООО «Биоссет» (Россия).

Полимеразную цепную реакцию (ПЦР) проводили в реакционной смеси объемом 20 мкл, содержащей 60-130 нг геномной ДНК, 67 мМ трис-HCl (pH 8.8), 2 мкл 1.8 мM MgCl $2,0.25$ мкл каждого dNTP, по 0.25 мкМоль каждого микросателлитного праймера, 1 единицу Taq полимеразы, в следующих условиях: после 2 мин денатурации при $94^{\circ} \mathrm{C}$ проводили 45 циклов, включавших 1 мин при $94^{\circ} \mathrm{C}, 1$ мин при $55^{\circ} \mathrm{C}$ (для маркера Hpsm 1-5) или $60^{\circ} \mathrm{C}$ (для маркеров Gpms93, Epms310, Epms331, Epms397 и Epms419) и 2 мин при $72{ }^{\circ} \mathrm{C}$. В конце программы амплификации проводили один пятиминутный цикл при $72{ }^{\circ} \mathrm{C}$. После окончания ПЦР продукты реакции разводили в соотношении 1:10. В новые микропробирки вносили 1 мкл разведенных продуктов реакции и высушивали в вакуумной сушилке при $45^{\circ} \mathrm{C}$ в течение 15 мин.

Анализ фрагментов ПЦР проводили с использованием генетического анализатора «Нанофор-05» (Синтол-ИАП, Россия) в ЦКП Сектор геномных исследований ИЦиГ СО РАН. Анализ данных осуществляли при использовании программного обеспечения Fragment v72. В качестве маркера длины использовали LIZ-500 (ThermoFisher Scientific, США).

Данные микросателлитного генотипирования использовали для кластерного анализа, который проводили с помощью онлайн-программы POPTREEW (http://poptree.med.kagawa-u.ac.jp) с использованием метода присоединения соседей. Устойчивость узлов оценивали с помощью бутстреп-анализа на основе 1000 случайных выборок.

Выделение антоцианов и оценка антиоксидантной активности Анализ содержания доступных при питании человека антоцианов и суммарного содержания антиоксидантов (ССА) проводили в созревших плодах (в подвяленном виде), выращенных в условиях гидропонной теплицы ЦКП «Лаборатория искусственного выращивания растений» ИЦиГ СО РАН. Экстрагирование антоцианов проводили в условиях, приближенных к таковым при усвоении пищи в желудочно-кишечном тракте (ЖКТ). К мелкоизмельченному образцу (1 г), добавляли 20 мл 1 \% водного раствора $\mathrm{HCL}$, перемешивали и инкубировали в течение одного часа при $37^{\circ} \mathrm{C}$. Каждый образец был представлен в трех повторностях. (Хлесткина и др., 2017). Затем экстракт фильтровали с помощью фильтра «Зеленая лента» (ООО Бавер) (Приложение 1). Полученный фильтрат использовали для оценки антиоксидантной активности на приборе «Близар» (Интерлаб, Россия) согласно инструкции производителя. Результат выражали в эквивалентах галловой кислоты (мкг-экв. ГК/г). Для оценки относительного содержания антоцианов проводили дополнительное центрифугирование в течение 15 мин при $4{ }^{\circ} \mathrm{C}$ со скоростью 12000 об./мин. Содержание антоцианов в полученном супернатанте измеряли с помощью спектрофотометра SmartSpec ${ }^{\text {TM }}$ Plus (BioRad, www.bio-rad.com) при длине волны 530-700 нм по методу, описанному ранее (Abdel-Aal, Hucl, 1999).

\section{Статистическая обработка результатов}

Значимость различий между образцами по изученным параметрам оценивали по среднему значению из трех последовательных измерений с помощью критерия Манна - Уитни (U-теста) (Mann, Whitney, 1947). Непараметрический критерий Краскела - Уоллиса (H-тест) (Kruskal, Wallis, 1952) был использован для определения влияния факторов «генотип» и «окраска плодов» на суммарное содержание антиоксидантов в водных экстрактах 1 \% HCI. Достоверность отличий между группами была протестирована с помощью критерия Тьюки (HSD-теста) (Tukey, 1949). Достоверными считали различия при $p \leq 0.05$. Степень взаимосвязи между параметрами оценивали с помощью коэффициентов ранговой корреляции Спирмена. Статистическую обработку результатов проводили с помощью программы Statistica 6.0 (StatSoft Inc., 2001).

\section{Результаты}

Генотипирование и кластерный анализ

C помощью SSR-маркеров, описанных в литературе, было проведено генотипирование десяти сортов перца. Для микросател- 
Таблица 3. Данные генотипирования сортов перца сладкого с помощью SSR-маркеров.

Указаны длины ПЦР-фрагментов в нуклеотидах

Table 3. Genotyping data of bell pepper cultivars with SSR-markers. The PCR-product length is indicated in nucleotides

\begin{tabular}{lllllll} 
Сорт & Epms310 & Epms331 & Epms397 & Epms419 & Gpms93 & Hpsm1-5 \\
Бегемот & 175 & 85 & 108 & 236 & 258 & 318 \\
\hline Гранатовый браслет & 174 & 80 & 108 & 234 & 252 & 321 \\
\hline Золото Сибири & 175 & 85 & 108 & 236 & 0 & 320 \\
\hline Кавалер & 174 & $84 / 105$ & 112 & 238 & 256 & 323 \\
\hline Красавец Приобья & 174 & 104 & 108 & 234 & 252 & 323 \\
\hline Мавр & 175 & 104 & 108 & 236 & 256 & 323 \\
\hline Солнечный & 173 & 83 & 108 & 233 & 258 & 324 \\
\hline Сибирский князь & 175 & $84 / 105$ & 108 & 240 & 256 & 323 \\
\hline Сибирский экспресс & 174 & 104 & 116 & 234 & 0 & 320 \\
\hline Ятаган & 174 & $85 / 104$ & 108 & 234 & 0 & 320 \\
\hline
\end{tabular}

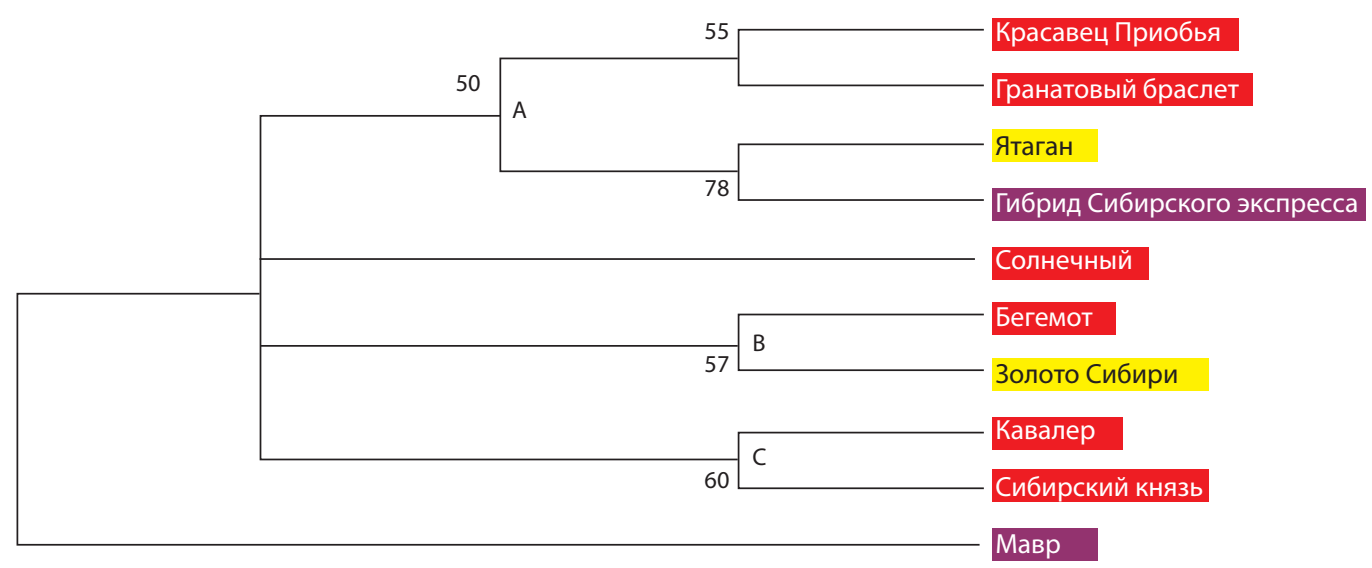

Рис. 2. Кластерный анализ сортов сладкого перца сибирской селекции на основе данных микросателлитного генотипирования. Цифрами отмечены значения бутстреп-поддержки узлов ветвления в процентах, рассчитанные на основе 1000 случайных выборок.

Figure 2. Cluster analysis of bell pepper cultivars bred for Siberia based on microsatellite genotyping. The numbers mark bootstrap values for nodes counted using 1000 independent iterations.

литных маркеров Epms310 и Epms397 выявлено три аллельных варианта; для Gpms93 - четыре. Самыми полиморфными в изучаемой коллекции перцев оказались следующие маркеры: Epms419шесть, Hpsm1-5 - шесть, Еpms331 - семь аллелей. У сортов Кавалер, Сибирский князь и Ятаган маркер Epms331 был представлен в гетерозиготном состоянии (табл. 3).

Данные микросателлитного генотипирования были использованы для кластерного анализа (рис. 2). Десять сортов перца были разделены на три кластера, бутстреп-поддержка внутренних узлов которых превышала 50 \%. В кластер $А$ вошли Красавец Приобья, Гранатовый браслет и Ятаган, Сибирский экспресс, которые были сгруппированы попарно. В кластер В вошли Бегемот и Золото Сибири, а в кластер C-Кавалер и Сибирский князь. Сорта Мавр и Солнечный не вошли ни в один из кластеров, что указывает на их генетическую удаленность от других сортов перца, в том числе друг от друга.
Количественная оценка антоцианов и суммарное содержание антиоксидантов

Относительное содержание антоцианов в нарезанных ножом плодах перца после часовой экстракции в водном растворе $1 \% \mathrm{HCl}$, измеренное при оптической плотности OD530-700, варьировало от 0.008 у красноплодного Гранатового браслета до 0.041 у фиолетовоплодного Мавра. Наибольшие значения оптической плотности раствора 0.024 и 0.041 при изучаемой длине волны были отмечены для фиолетово-красных плодов гибрида Сибирского экспресса и фиолетовых плодов Мавра соответственно (рис. 3).

Суммарное содержание антиоксидантов в цветных перцах варьировало от 0.62 мкг/г у красноплодного Бегемота до 1.54 мкг/г у фиолетово-красноплодного гибрида Сибирского экспресса (рис. 4). При попарном сравнении ССА в экстрактах плодов перца различных сортов были выявлены как достоверные различия 


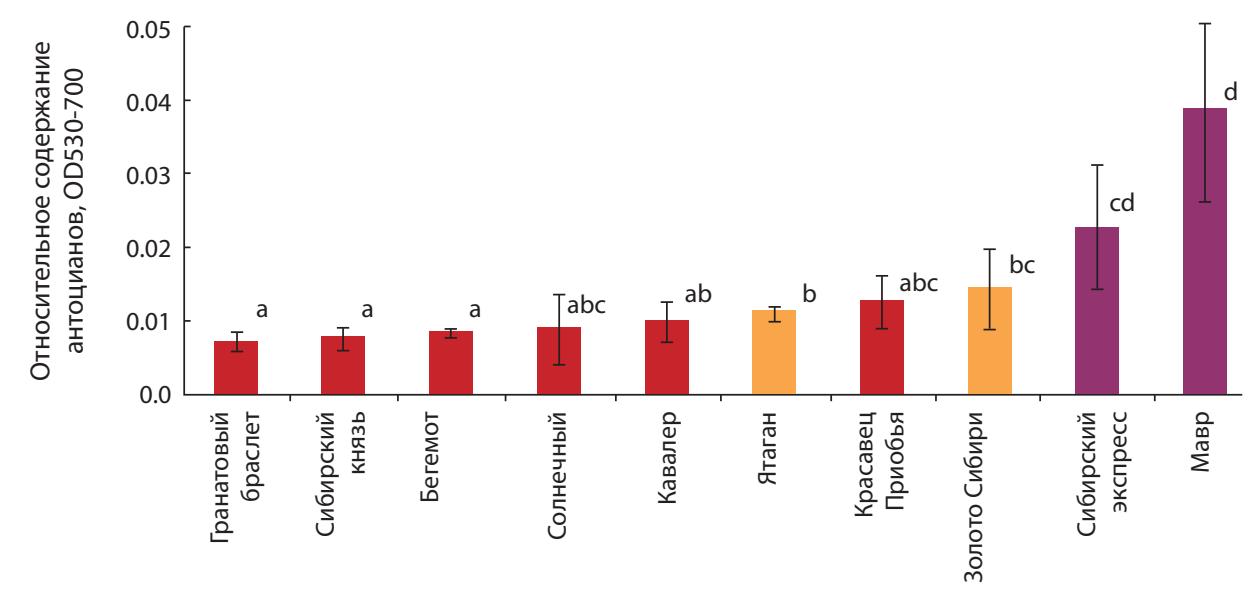

Pис. 3. Оптическая плотность раствора антоцианов после часовой экстракции в 1 \% растворе $\mathrm{HCl}$ при $37^{\circ} \mathrm{C}$. Разными буквами отмечены достоверно отличающиеся значения между сортами при $p \leq 0.05$ (U-тест).

Figure 3. Optical density of anthocyanin extracts obtained after one hour extraction in $1 \%$ solution of $\mathrm{HCl}$ under $37^{\circ} \mathrm{C}$. Different letters mark statistically significant differences between cultivars at $p \leq 0.05$ (U-test).

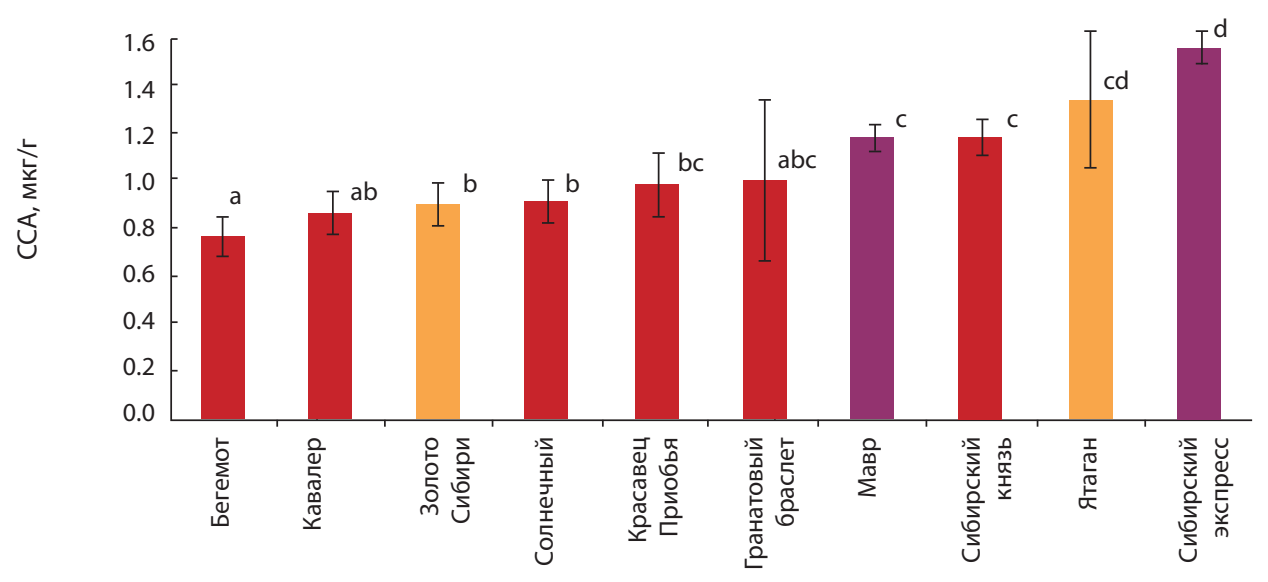

Рис. 4. Суммарное содержание антиоксидантов после часовой экстракции в $1 \%$ растворе $\mathrm{HCl}$ при $37^{\circ} \mathrm{C}$. Разными буквами отмечены достоверно отличающиеся значения между сортами при $p \leq 0.05$ (U-тест). Figure 4. Total antioxidant content after one hour extraction in $1 \%$ solution of $\mathrm{HCl}$ under $37^{\circ} \mathrm{C}$. Different letters mark statistically significant differences between cultivars at $p \leq 0.05$ (U-test).

между сортами, имеющими одинаковую окраску плода (например, Бегемот vs Солнечный vs Сибирский князь, Золото Сибири vs Ятаган, Мавр vs гибрид Сибирского экспресса), так и отсутствие различий между сортами, обладающими разной пигментацией, например, Золото Сибири vs Солнечный, Мавр vs Сибирский князь vs Ятаган (см. рис. 4). Для того чтобы оценить, существует ли взаимосвязь между содержанием антоцианов и антиоксидантным потенциалом экстрактов, был проведен корреляционный анализ, показавший наличие слабой корреляции между концентрацией антоцианов и суммарным содержанием антиоксидантов $\left(r_{s}=0.41\right.$, $p \leq 0.05)$. С помощью непараметрического критерия Краскела - Уоллиса было показано, что фактор «генотип» оказывает влия- ние на антиоксидантный статус экстрактов перца (табл. 4). Между группами перцев из кластеров $A$ и $B$ были выявлены достоверные отличия ( $p=0.0217, H S D$-тест). При группировании сортов по их окраске и тестировании фактора «окраска плода» было обнаружено, что этот фактор оказывает влияние на антиоксидантный статус экстрактов перца. Наибольшей антиоксидантной активностью обладали экстракты, полученные из фиолетовоплодных перцев, а наименьшей - из красноплодных. Желтоплодные перцы занимали промежуточное положение по своей антиоксидантной активности. Между группой фиолетово- и красноплодных перцев были отмечены статистически достоверные отличия ( $p=0.0015$, HSD-тест, Приложение 2). 
Таблица 4. Н-тест Краскела - Уоллиса: оценка влияния различных факторов на суммарное содержание антиоксидантов у перцев сладких сибирской селекции

Table 4. Kruskal - Wallis $H$-test: effect of different factors on total antioxidant content in bell peppers bred for Siberia

\begin{tabular}{|c|c|c|c|c|c|c|c|}
\hline Фактор & Группы & Размер группы & Сумма рангов & df & $H$ & $\begin{array}{l}p \text {-уровень } \\
\text { значимости }\end{array}$ & $\begin{array}{l}\text { Влияние } \\
\text { фактора }\end{array}$ \\
\hline \multirow[b]{3}{*}{ Генотип } & Кластер A & 12 & 244 & \multirow[b]{3}{*}{4} & \multirow[b]{3}{*}{12.04} & \multirow[b]{3}{*}{0.0171} & \multirow[b]{3}{*}{ да } \\
\hline & Кластер В & 6 & 39 & & & & \\
\hline & Кластер C & 6 & 87 & & & & \\
\hline \multirow{3}{*}{ Окраска плода } & Желтые & 6 & 101 & \multirow{3}{*}{2} & \multirow{3}{*}{9.16} & \multirow{3}{*}{0.0102} & \multirow{3}{*}{ да } \\
\hline & Красные & 18 & 217 & & & & \\
\hline & Фиолетовые & 6 & 147 & & & & \\
\hline
\end{tabular}

\section{Обсуждение}

Ранее проведенные исследования показали, что антиоксидантный потенциал плодов перца определяется концентрацией аскорбиновой кислоты, а также фракциями водо- и жирорастворимых соединений, содержание которых может существенно варьировать между различными сортами перца и зависит от стадии зрелости плода, его цвета и условий произрастания (Lee et al., 1995; Howard et al., 2000; Fox et al., 2005; Sun et al., 2007; Frary et al., 2008; Nadeem et al., 2011). В данном исследовании была проведена оценка концентрации водорастворимых пигментов антоцианов, относящихся к фракции фенольных соединений, которые, согласно A.K. Blanco-Ríos c коллегами (2013), вносят наибольший вклад в антиоксидантный потенциал перцев по сравнению с фракцией жирорастворимых антиоксидантов. Чтобы оценить долю антоцианов, доступных для усвоения в организме человека, их экстрагирование проводили в условиях, максимально приближенных к условиям в ЖКТ (Хлесткина и др., 2017). Было показано, что суммарное содержание фракции водорастворимых антиоксидантов варьировало между сортами перца, различия могли достигать двукратного значения, при этом наибольшее ССА было детектировано в экстракте из фиолетово-красных перцев гибрида Сибирского экспресса, накапливающего как красные каротиноиды, так и фиолетовые антоцианы (см. рис. 1 и 3). Между содержанием антоцианов и ССА была выявлена слабая, но статистически достоверная корреляция $\left(r_{s}=0.41, p \leq 0.05\right)$, что указывает на то, что другие соединения, которые экстрагировали совместно с антоцианами, также вносят вклад в ССА. В ряде работ была показана положительная корреляция между антиоксидантной активностью и суммарным содержанием фенольных соединений в свежих плодах перца и продуктах их переработки (Yao et al., 2010; Zhuang et al., 2012; Medina-Juárez et al., 2012; Chávez-Mendoza et al., 2015). Однако в некоторых исследованиях такой корреляции не обнаружено (Campos et al., 2013). Между содержанием каротиноидов и антиоксидантной активностью наблюдались, в зависимости от сорта, как положительная, так и отрицательная корреляции (Chávez-Mendoza et al., 2015). Помимо фенольных соединений и каротиноидов положительная корреляция была выявлена между CCA и концентрацией аскорбиновой кислоты (Chávez-Mendoza et al., 2015). Как показано, генетическая изменчивость между сорта- ми оказывает существенное влияние на антиоксидантную активность плодов перцев.

В нашей работе для того, чтобы оценить, влияют ли факторы «генотип» и «окраска плодов» на антиоксидантную активность перцев, изучаемые сорта были объединены в группы на основе их ко-кластеризации на дендрограмме, сконструированной по данным микросателлтиного анализа (см. рис. 2), и окраски плодов соответственно. С помощью теста Краскела - Уоллиса было показано статистически достоверное влияние этих факторов на ССА (табл. 4). Для кластеров $A$ и $B$ характерна наибольшая и наименьшая антиоксидантная активность соответственно. При тестировании влияния окраски было установлено, что фиолетовоплодные сорта перца имели наибольшую антиоксидантную активность, статистически достоверно отличающуюся от таковой у красноплодных перцев. Группа желтых перцев по суммарному содержанию антиоксидантов занимала промежуточное положение между фиолетово- и красноплодными перцами и статистически не отличалась от них. В работе Т. Sun с коллегами (2007) было показано, что среди зеленых, желтых, оранжевых и красных перцев самой низкой антиоксидантной активностью обладают зеленые перцы, характеризующиеся самым низким суммарным содержанием фенольных соединений и лютеолина по сравнению с перцами, окрашенными каротиноидами, и полным отсутствием капсантина, тогда как между остальными окрашенными перцами существенных отличий в антиоксидантной активности не выявлено. Хотя, в отличие от упомянутой работы, в представленном исследовании проведена оценка только водорастворимой фракции антиоксидантов, полученные нами данные подтверждают выводы, сделанные T. Sun с коллегами, изучавшими весь пул антиоксидантов плодов перца.

\section{Заключение}

Проведенное исследование антиоксидантной активности десяти сортов перца сладкого сибирской селекции, имеющих желтую, красную и фиолетовую окраску плодов, подтверждает выводы о том, что на суммарное содержание антиоксидантов перца оказывают влияние генотип и окраска плода. Впервые показано, что фиолетовоплодные сорта перцев имеют наибольшее содержание 
водорастворимых антиоксидантов, доступных для усвоения в организме человека, что делает их особенно привлекательными в качестве функциональных продуктов питания.

\section{Список литературы / References}

Фотев Ю.В., Пивоваров В.Ф., Артемьева А.М., Куликов И.М., Гончарова Ю.К. Сысо А.И., Гончаров Н.П. Концепция создания Российской национальной системы функциональных продуктов питания. Вавиловский журнал генетики и селекции. 2018;22(7):776-783. DOI: 10.18699/VJ18.421.

[Fotev Yu.V., Pivovarov V.F., Artemyeva A.M., Kulikov I.M., Goncharova Y.K., Syso A.I., Goncharov N.P. [Concept of producing of the Russian national system of functional food]. Vavilovskii Zhurnal Genetiki i Selektsii = Vavilov Journal of Genetics and Breeding. 2018;22(7):776-783. DOI: 10.18699/VJ18.421. (in Russian)]

Хлесткина Е.К., Усенко Н.И., Гордеева Е.И., Стабровская О.И., Шарфунова И.Б., Отмахова Ю.С. Маркер-контролируемое получение и производство форм пшеницы с повышенным уровнем биофлавоноидов: оценка продукции для обоснования значимости направления. Вавиловский журнал генетики и селекции. 2017;21(5):545-553. DOI: 10.18699/VJ17.25-о.

[Khlestkina E.K., Usenko N.I., Gordeeva E.I., Stabrovskaya O.I., Sharfunova I.B., Otmakhova Y.S. Evaluation of wheat products with high flavonoid content: justification of importance of marker-assisted development and production of flavonoid-rich wheat cultivars. Vavilovskii Zhurnal Genetiki i Selektsii = Vavilov Journal Genetics Breeding. 2017;21(5):545-553. DOI: 10.18699/ VJ17.25-o. (in Russian)]

Abdel-Aal E.-S.M., Hucl P. A rapid method for quantifying total anthocyanins in blue aleurone and purple pericarp wheats. Cereal Chem. 1999;76(3):350354. DOI: 10.1094/CCHEM.1999.76.3.350.

Ahuja K.D., Robertson I.K., Geraghty D.P., Ball M.J. Effects of chili consumption on postprandial glucose, insulin, and energy metabolism. Am. J. Clin. Nutr. 2006;84(1):63-69. DOI: 10.1093/ajcn/84.1.63.

Basu S.K., De A.K. Capsicum: historical and botanical perspectives: De A.K. (ed). Capsicum. The Genus Capsicum. London, UK, Taylor Francis Group. 2003;115. DOI: 10.1201/9780203381151-8.

Blanco-Ríos A.K., Medina-Juarez L.A., González-Aguilar G.A., Gamez-Meza N. Antioxidant activity of the phenolic and oily fractions of different sweet bell peppers. Journal Mexican Chemical Society. 2013;57(2):137-143. DOI: 10.29356/jmcs.v57i2.226.

Campos M.R.S., Gomez K.R., Ordonez Y.M., Ancona D.B. Polyphenols, ascorbic acid and carotenoids contents and antioxidant properties of habanero pepper (Capsicum chinense) fruit. Food Nutrition Sci. 2013;4(8):47-54. DOI: 10.4236/fns.2013.48A006.

Chávez-Mendoza C., Sanchez E., Muñoz-Marquez E., Sida-Arreola J.P., FloresCordova M.A. Bioactive compounds and antioxidant activity in different grafted varieties of bell pepper. Antioxidants (Basel). 2015;4(2):427-446. DOI: 10.3390/antiox4020427.

Fox A.J., Del Pozo-Insfran D., Lee J.H., Sargent S.A., Talcott S.T. Ripening-induced chemical and antioxidant changes in bell peppers as affected by harvest maturity and postharvest ethylene exposure. HortScience. 2005;40(3):732736. DOI: $10.21273 /$ hortsci.40.3.732.

Frary A., Keceli M.A., Okmen B., Sigva H.O., Yemenicioglu A., Doganlar S. Water-soluble antioxidant potential of Turkish pepper cultivars. Hort Sci. 2008;43(3):631-636. DOI: 10.21273/HORTSCI.43.3.631.
Howard L.R., Talcott S.T., Brenes C.H., Villalon B. Changes in phytochemical and antioxidant activity of selected pepper cultivars (Capsicum species) as influenced by maturity. J. Agric. Food Chem. 2000;48(5):1713-1720. DOI: 10.1021/ jf990916t.

Kruskal W.H., Wallis W.A. Use of ranks in one-criterion variance analysis. J. Am. Stat. Assoc. 1952;47(260):583-621. DOI: 10.2307/2280779.

Lee J.M., Nahm S.H., Kim Y.M., Kim B.D. Characterisation and molecular genetic mapping of microsatellite loci in pepper. Theor. Appl. Genet. 2004;108(4):619627. DOI: 10.1007/s00122-003-1467-x.

Lee Y., Howard L.R., Villalon B. Flavonoids and antioxidant activity of fresh pepper (Capsicum annuum) cultivars. J. Food Sci. 1995;60(3):473-476. DOI: 10.1111/j.1365-2621.1995.tb09806.x.

Liu Y., Tikunov Y., Schouten R.E., Marcelis L.F.M., Visser R.G.F., Bovy A. Anthocyanin biosynthesis and degradation mechanisms in solanaceous vegetables: a review. Frontiers Chemistry. 2018;6(52):1-17. DOI: 10.3389/ fchem.2018.00052.

Mann H.B., Whitney D.R. On a test of whether one of two random variables is stochastically larger than the other. Ann. Math. Stat. 1947;18(1):50-60. http://www.jstor.org/stable/2236101.

Meghvansi M.K., Siddiqui S., Khan M.H., Gupta V.K., Vairale M.G., Gogoi H.K., Singh L. Naga chilli: A potential source of capsaicinoids with broadspectrum ethnopharmacological applications. J. Ethnopharmacol. 2010;132(1):1-14. DOI: 10.1016/j.jep.2010.08.034.

Medina-Juárez L.A., Molina-Quijada D.M.A., Del Toro-Sanches C.L., GonzálezAguilar G.A., Gámez-Meza N. Antioxidant activity of peppers (Capsicum annuum L.) extracts and characterization of their phenolic constituents. Interciencia. 2012;37(8):588-593.

Nadeem M., Anjum F.M., Khan M.R., Saeed M., Riaz A. Antioxidant potential of Bell Pepper (Capsicum annuum L.) - A Review. Pak. J. Food Sci. 2011;21(1-4):45-51.

Nagy I., Stágel A., Sasvári Z., Röder M.S., Ganal M. Development, characterization, and transferability to other Solanaceae of microsatellite markers in pepper (Capsicum annuum L.). Gen. 2007;50(7):668-688. DOI: 10.1139/g07-047.

Ohmiya A., Kato M., Shimada T., Nashima K., Kishimoto S., Nagata M. Molecular basis of carotenoid accumulation in horticultural crops. Horticulture Journal. 2019;88(2):135-149. DOI: 10.2503/hortj.UTD-R003.

Rao A.V., Rao L.G. Carotenoids and human health. Pharmacol. Res. 2007;55(3):207-216. DOI: 10.1016/j.phrs.2007.01.012.

Sun T., Xu Z., Wu C.-T., Janes M., Prinyawiwatkul W., No H.K. Antioxidant activities of different colored sweet bell peppers (Capsicum annuum L.). J. Food Sci. 2007;72(2):S98-S102. DOI: 10.1111/j.1750-3841.2006.00245.x.

Tukey J.W. Comparing individual means in the analysis of variance. Biometrics. 1949;5(2):99-114. DOI: 10.2307/3001913.

Yao Y., Sang W., Zhou M., Ren G. Phenolic composition and antioxidant activities of 11 celery cultivars. J. Food Sci. 2010;75(1):C9-C13. DOI: 10.1111/j.17503841.2009.01392.x.

Zhuang Y., Chen L., Sun L., Cao J. Bioactive characteristics and antioxidant activities of nine peppers. J. Funct. Foods. 2012;4(1):331-338. DOI: 10.1016/j. jff.2012.01.001.

Zimmer A.R., Leonardi B., Miron D., Schapoval E., Oliveira J.R., Gosmann G. Antioxidant and anti-inflammatory properties of Capsicum baccatum: From traditional use to scientific approach. J. Ethnopharmacol. 2012;139(1):228-233. DOI: 10.1016/j.jep.2011.11.005.

\section{ORCID ID}

Igor' V. Totsky https://orcid.org/0000-0001-5565-9097

Elena I. Gordeeva https://orcid.org/0000-0003-3166-7409

Rimma S. Yudina https://orcid.org/0000-0001-7345-359

Elena K. Khlestkina http://orcid.org/0000-0002-8470-8254

Olesya Yu. Shoeva https://orcid.org/0000-0001-5289-8631

Конфликт интересов. Авторы заявляют об отсутствии конфликта интересов.

Для цитирования. Тоцкий И.В., Гордеева Е.И., Кукоева Т.В., Петров А.Ф., Юдина Р.С., Хлесткина Е.К., Шоева О.Ю. Генетическое разнообразие и антиоксидантный потенциал сортов перца сладкого (Сарsicum annuum L.) сибирской селекции. Письма в Вавиловский журнал генетики и селекции. $2019 ; 5(1): 35-43$. DOI 10.18699/Letters2019-5-5.

For citation. Totsky I.V., Gordeeva E.I., Kukoeva T.V., Petrov A.F., Yudina R.S., Khlestkina E.K., Shoeva O.Yu. Genetic diversity and antioxidant properties of the bell pepper (Capsicum annuum L.) cultivars bred for Siberia Pisma v Vavilovskii Zhurnal Genetiki i Selektsii = Letters to Vavilov Journal of Genetics and Breeding. 2019;5(1):3543. DOI 10.18699/Letters2019-5-5. (in Russian)

Поступила в редакцию 15.10.2019. После доработки 29.10.2019. Принята к публикации 29.11.2019. 


\section{ПРИЛОЖЕНИЕ 1}

\section{SUPPLEMENT 1}
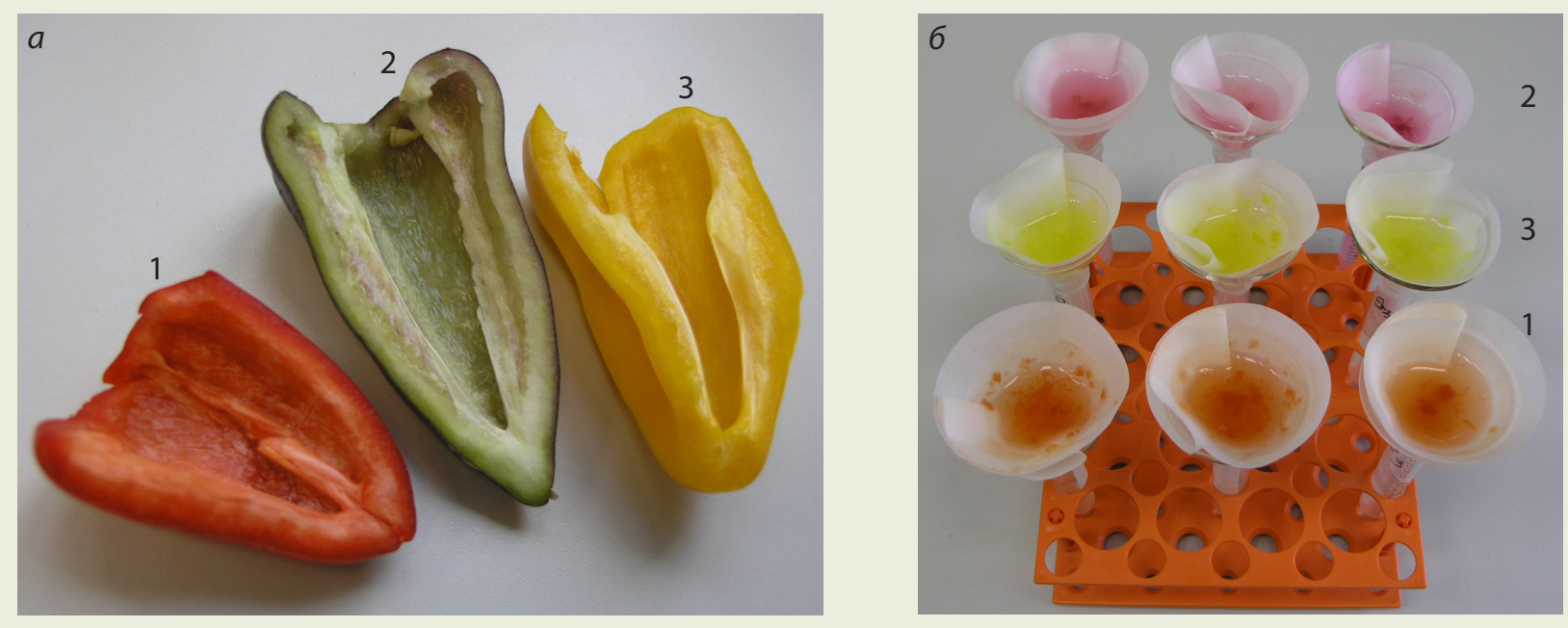

Красно-, фиолетово- и желтоплодные перцы в разрезе (А) и фильтрование их экстрактов после часового экстрагирования в водном растворе $1 \% \mathrm{HCl}$ при $37^{\circ} \mathrm{C}$ (Б). Цифрами отмечены сорта перца Солнечный (1), Мавр (2) и Ятаган (3).

Sections of red, purple and yellow peppers (A) and filtration of their extracts (B) obtained after one hour extraction in $1 \%$ solution of hydrochloric acid under $37^{\circ} \mathrm{C}$. Numbers mark Solnechnyj (1), Mavr (2), Yatagan (3).

\section{ПРИЛОЖЕНИЕ 2}

\section{SUPPLEMENT 2}

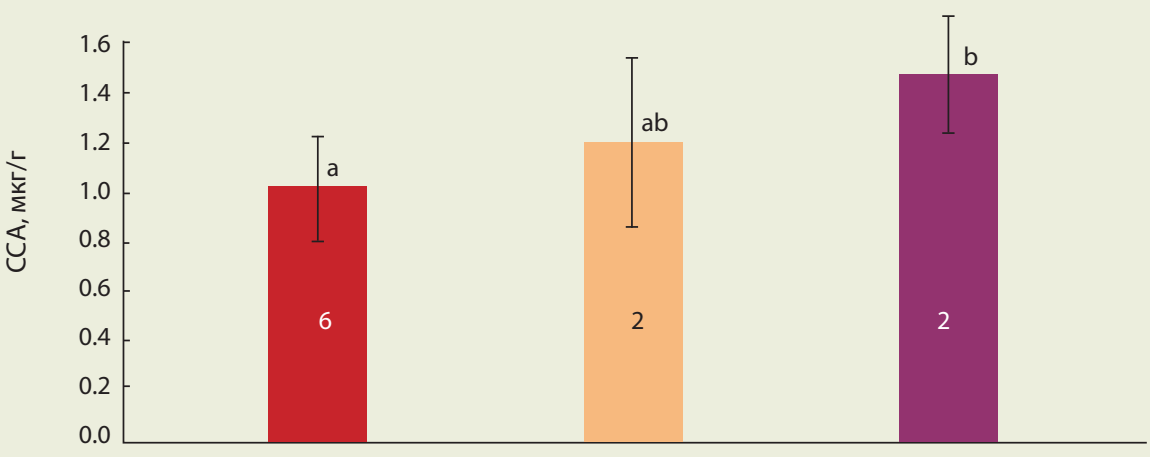

Суммарное содержание антиоксидантов в группе красно-, желто- и фиолетовоплодных сортов перца сладкого после часовой экстракции в $1 \%$ растворе $\mathrm{HCl}$ при $37^{\circ} \mathrm{C}$. Разными буквами отмечены достоверно отличающиеся значения между группами при $p \leq 0.05$ (HSD-тест). Цифрами отмечено количество сортов в каждой группе.

Total antioxidant content in groups of red, yellow and purple pepper cultivars after one hour extraction in $1 \%$ solution of $\mathrm{HCl}$ under $37^{\circ} \mathrm{C}$. Different letters mark statistically significant differences between cultivars at $p \leq 0.05$ (HSD-test). Numbers mark quantity of cultivars in each group. 